\title{
A constituição do espaço público e o perfil democrático das bibliotecas
}

\author{
The constitution of public space and the democratic profile of libraries
}

\begin{abstract}
Willian Eduardo Righini de Souza
Doutor em Ciência da Informação pela Escola de Comunicações e Artes da Universidade de São Paulo ECA/USP, Brasil.

Bibliotecário-Documentalista do Instituto Federal de Educação, Ciência e Tecnologia de São Paulo, Brasil. E-mail: wrighini@yahoo.com.br
\end{abstract}

\begin{abstract}
Resumo
Ao longo do século XX, diferentes autores apontaram o declínio do espaço público, reduzindo as possibilidades dos cidadãos se reunirem para dialogar a partir de argumentos racionais. Entre as poucas instituições de acesso gratuito, que disponibilizam a consulta a documentos e oferecem oportunidades para o aprendizado e convívio entre diferentes está a biblioteca pública. Desse modo, discutimos a contribuição dessa instituição para o fortalecimento da democracia, sendo um lugar onde os cidadãos podem ter contato com especialistas, consultar uma variedade de fontes e confrontar ideias e concepções de mundo a partir das atividades realizadas em seu espaço. Por meio de uma abordagem qualitativa da bibliografia selecionada, que inclui de autores consolidados nas Ciências Sociais a recentes pesquisas em Ciência da Informação, analisamos a capacidade de a biblioteca se constituir em um espaço público e estimular a ação coletiva. Diante da pouca valorização da biblioteca pública na atualidade, defendemos que a perspectiva adotada reforça a importância dessa instituição para a vida em comum e para o engajamento social.
\end{abstract}

Palavras-chave: Biblioteca pública. Espaço público. Democracia.

\begin{abstract}
Throughout the twentieth century, different authors pointed to the decline of public space, reducing the possibilities for citizens to come together to dialogue based on rational arguments. Among the few free institutions that offer document consultation, opportunities for learning and socializing among different people is the public library. Thus, we discuss the contribution of this institution to the strengthening of democracy, being a place where citizens can have contact with experts, consult a variety of sources and confront ideas and conceptions of the world from the activities performed in their space. Through a qualitative approach of the selected bibliography, which includes from authors consolidated in Social Sciences to recent research in Information Science, we analyze the capacity of the library to be a public space and stimulate collective action. Given the low appreciation of the public library nowadays, we argue that the perspective adopted reinforces the importance of this institution for life in common and for social engagement.
\end{abstract}

Keywords: Public library. Public space. Democracy. 


\section{Introdução}

Em 2019, o Brasil possuía mais de 6050 bibliotecas públicas, segundo dados do Sistema Nacional de Bibliotecas Públicas - $\mathrm{SNBP}^{1}$. Muitas delas se encontram em prédios inadequados, possuem acervos desatualizados e precisariam de mais funcionários. Porém, não se verifica uma mobilização social ou política de grande envergadura para reverter esse quadro de abandono. Se, de modo geral, a biblioteca é vista como uma instituição que contribui para a educação e o entretenimento da população, a falta de investimentos não causa repercussão na imprensa, pressão a políticos e manifestações públicas, a não ser em casos muito específicos nos grandes centros. Desse modo, pode causar estranheza defender que a biblioteca pública tem condições de exercer um papel de destaque no fortalecimento e promoção da democracia.

Sem investimentos, bibliotecas podem se tornar um depósito de livros, não convidativas às novas gerações e preparadas para atender as demandas informacionais contemporâneas. Ao mesmo tempo, observa-se um declínio do espaço público nas últimas décadas. Em uma lógica capitalista, pergunta-se qual a razão de se investir em bibliotecas públicas se elas não geram lucro.

As novas tecnologias de informação e comunicação diminuíram a necessidade das pessoas se deslocarem para interagir com outros seres humanos, mas não conseguiram substituir o espaço público. Pelo contrário, elas facilitaram o surgimento de comunidades fechadas que fragilizam o processo democrático. Desse modo, há um menor estímulo ao convívio social presencial e ao confronto de ideias para a busca de soluções coletivas.

Enquanto instituição pública gratuita que disponibiliza fontes de informação e que promove ações para facilitar o compartilhamento de conhecimentos e experiências entre pessoas e grupos de diferentes perfis, a biblioteca desponta como uma possibilidade para o fortalecimento do espaço público. Se ainda hoje são utilizados critérios como o número de usuários e de empréstimos para avaliar a relevância de uma biblioteca, novas reflexões têm buscado compreender o impacto dessa instituição na localidade onde ela se encontra, a sua contribuição para a inclusão social e, sobretudo, para a criação de espaços onde as pessoas possam se reunir, debater, conhecer opiniões divergentes e, a partir desse convívio, estabelecer condições para a ação.

\footnotetext{
${ }^{1}$ Disponível em: http://snbp.cultura.gov.br/bibliotecaspublicas/. Acesso em: 24 ago. 2019.
} 
Por meio de uma pesquisa qualitativa de caráter exploratório, visamos assinalar a biblioteca pública como uma instituição adequada para responder aos desafios de participação democrática e valorização do espaço público na contemporaneidade. Para tanto, recorremos a uma análise bibliográfica de publicações que discutem, sobretudo no exterior, a função das bibliotecas públicas e as suas possíveis contribuições para a democracia. Antes, para expor a conjuntura dessa discussão e as bases teóricas dos termos adotados, apresentamos algumas das principais abordagens sobre o declínio do espaço público ao longo do século XX.

Diante das dificuldades de se estabelecer, diversificar, oferecer a todos e valorizar os espaços públicos, sendo uma situação que extrapola os problemas enfrentados pelas bibliotecas e a falta de consenso sobre o papel político dessa instituição no presente e no futuro próximo, não propomos definir um modelo a ser adotado, mas defender a necessidade de maiores discussões sobre as bibliotecas públicas enquanto agentes de mobilização social e de sustentação da democracia.

\section{O declínio do espaço público}

O declínio do espaço público como conhecemos hoje faz parte de um processo que remonta ao século XIX. Sennett (2018a) sublinha que o capitalismo industrial criou condições para transformações profundas na sociedade burguesa, como a produção padronizada de produtos e vestimentas, o crescimento das cidades e o deslocamento de trabalhadores para grandes centros urbanos. Já no século XVII, as grandes capitais começaram a se estabelecer como um lugar de estranhos e desconhecidos. Em um momento de instabilidade e rápidas mudanças, a família se tornou um refúgio contra as ameaças do espaço público, uma busca por estabilidade e segurança.

O aparecimento e aperfeiçoamento de novos meios de transportes permitiram não apenas a viagem de mercadorias, mas uma menor dependência das pessoas aos seus lugares de origem e a possibilidade de se locomover sem considerar os detalhes do caminho. Entre o ponto de partida e chegada, moradias e pessoas se tornaram uma imagem borrada e homogênea. As cidades, como a Paris de Haussmann, ganharam grandes vias. Caminhos tortuosos que garantiam uma maior interação com as construções, objetos e transeuntes foram substituídos por trajetos mais adequados a veículos. Assim, o planejamento urbano buscou estabelecer uma 
ordem, nem que fosse ao custo das relações sociais, separando as classes e determinando uma função para cada lugar².

Habermas (2014) entende que o crescimento das cidades e a industrialização contribuíram para o fim do espaço público como lugar de discussão racional e crítica sobre questões compartilhadas. Enquanto, durante o século XVIII, periódicos e semanários favoreceram o surgimento de salões, cafés e círculos nos quais as elites se reuniam para se socializar e debater temas políticos e sociais, o século XIX, com a crescente industrialização e urbanização, foi o período de uma expansão da esfera pública que tornou difícil ou mesmo inviável discussões críticas e racionais entre pessoas de diferentes grupos para alcançar um bem comum.

A alienação do trabalho, a necessidade de deslocamentos em busca de opções de vida mais propícias e o surgimento de uma indústria cultural teriam transformado, na perspectiva de Habermas (2014), o público crítico em um público consumidor passivo. A vida moderna não apresentaria condições para a manutenção de uma esfera pública burguesa, mas facilitaria o controle das massas a partir da despolitização, da dependência econômica e dos meios de comunicação.

Arendt (2019) compartilha da compreensão de que o trabalhador-consumidor moderno, que se subordina ao trabalho para a sobrevivência, não dispõe de condições para uma convivência social plural, aberta e reflexiva. Ao invés de alcançar o domínio político, se distinguindo em sua humanidade, o trabalhador se reduz ao papel de animal laborans, lutando pela vida do seu corpo. Sem liberdade, ele não consegue se vincular aos seus semelhantes nem se beneficiar do uso do discurso e da ação coletiva.

Desse modo, a existência de um espaço público e, consequentemente, político só é possível pela união dos homens, a coexistência de diferentes visões de mundo, a diversidade de argumentos elaborados a partir da reflexão e do debate e, sobretudo, o reconhecimento do outro, o que é um desafio nas sociedades de massas. $\mathrm{O}$ homem isolado, incapaz de criar um mundo

\footnotetext{
${ }^{2}$ Os bulevares parisienses, com seus terraços, cafés e enormes calçadas, foram construídos com a expectativa de facilitar encontros, estimular conversações e enriquecer a vida social burguesa. No entanto, conforme o comércio e o tráfego cresciam, mais difícil se tornava a circulação. Como os bulevares foram pavimentados com macadame, eles ficavam poeirentos no verão e enlameados no inverno, causando desconfortos aos pedestres. Assim, andar a pé pelos bulevares exigia um espírito de aventura e coragem em meio ao caos. "O homem moderno arquetípico, como o vemos aqui, é o pedestre lançado no turbilhão do tráfego da cidade moderna, um homem sozinho, lutando contra um aglomerado de massa e energia pesadas, velozes e mortíferas.” (BERMAN, 2007, p. 190).
} 
comum por estar preso aos seus esforços pela sobrevivência, se torna indefeso ou mesmo indiferente à implantação de diferentes tipos de totalitarismos.

Em reflexões posteriores, Habermas (2014) adota uma postura menos pessimista e questiona a possibilidade de associações de base voluntária, não subordinadas ao Estado e a grupos econômicos, promoverem a comunicação pública, restabelecendo a ação política entre cidadãos aptos para compreender e apresentar argumentos racionais. De todo modo, não chega a uma conclusão sobre como a sociedade civil pode estabelecer uma esfera pública com condições de suportar as pressões de grupos de poder que minam a sua liberdade e a sua capacidade de diálogo assim como de garantir oportunidades iguais e formação para que indivíduos privados possam participar da esfera pública.

Durante o século XIX, arquitetos buscaram criar alternativas para a vida social nas grandes cidades. Na Inglaterra, Ebenezer Howard concebeu o modelo de cidade jardim com o objetivo de criar comunidades cercadas por uma área verde. Na Áustria, Camillo Sitte defendeu uma maior interação entre as construções e os espaços abertos, como as praças, valorizando os seus aspectos artísticos. Ao invés de projetar a cidade em grande escala, esses arquitetos focavam na existência de comunidades dentro das cidades. Segundo Sennett (2018a), os planejadores atuais não apenas abandonaram uma concepção global de cidade como, ao longo das últimas décadas do século $\mathrm{XX}$, preferiram projetos que colocam as comunidades contra a cidade. No Brasil, podemos citar o modelo de condomínios fechados.

Para Sennett (2018a), a formação dessas comunidades criam condições para a formação de guetos que limitam a interação com o mundo exterior. Ao mesmo tempo, se estabelece um sistema de vigilância e controle dentro da comunidade com o intuito de manter a sua unidade e segurança. As pressões para a coesão interna incentivam um comportamento hostil contra posições desviantes, podendo transformar a comunidade, prevista como uma oportunidade de sociabilidade, em um lugar de conflito e violência. Nessa perspectiva, Sennett (2018a) se opõe à ideia de que a formação de comunidades seria a resposta para o isolamento das pessoas nas grandes cidades.

O convívio social demanda certos riscos e a constituição de comunidades fechadas inibe o contato com o desconhecido. Fazer contatos fora do grupo exige o esforço de lidar com visões de mundo conflitantes, mas também oferece a chance de descobrir pontos de concordância. Um risco é a rejeição do grupo, que para tentar forjar a sua coesão recusa posicionamentos alternativos. No início do século XX, Halbwachs (2004, p. 58) já apontava que "um homem 
para evocar seu próprio passado, tem frequentemente necessidade de fazer apelo às lembranças dos outros", alimentando o que ele descreve como uma memória coletiva. Assim, o compartilhamento de memórias é um sinal de pertencimento e identidade entre membros de uma comunidade. Quando um indivíduo enaltece o diverso e se interessa por aquilo que, a princípio, não se enquadra nas construções sociais que ele e sua comunidade reconhecem, exigindo um esforço de ressignificação ou de elaboração de novas memórias a partir de outros laços e interações, ele pode ser visto como uma ameaça de ruptura e questionamento da ordem vigente.

Se a vida na cidade moderna, com as suas dimensões monumentais, os deslocamentos em veículos de alta velocidade e a alienação do trabalho, dificulta a sociabilidade, a proposta de criar comunidades em espaços delimitados não fez a cidade mais sociável, mas concretizou uma estratégia de negação do espaço urbano e de abertura para a diferença.

Nesse contexto, a valorização da impessoalidade é defendida por Sennett (2018a) para evitar os extremos que surgem tanto na comunidade fechada como na cidade hostil. Para ele, sem distanciamento e barreiras que estabelecem limites ao convívio social, as pessoas se tornam destrutivas, como ocorrem nos guetos. Sem o respeito à individualidade e a diferença, as pressões dentro de uma comunidade dificultam a troca espontânea de experiências. Ao mesmo tempo, ao se preservarem de relações mais intimistas, facilita-se o convívio com os outros, podendo compartilhar o mesmo espaço. A impessoalidade se constituiu em uma proteção para interagir com o desconhecido. Nesse sentido, ela se apresenta como um estímulo à sociabilidade e não o contrário.

\begin{abstract}
A renovação da cidade, a rejeição das cadeias do bairrismo - que foram forjadas primeiramente no século XIX e que hoje em dia se tornaram um credo -, é também a renovação de um princípio de comportamento político. A extensão em que as pessoas podem aprender a perseguir agressivamente seus interesses em sociedade é a extensão em que elas aprendem a agir de modo impessoal. A cidade deveria ser mestra nesse modo de agir, o fórum no qual se torna significativo unir-se a outras pessoas sem a compulsão de conhecê-las enquanto pessoas. No creio que esse seja um sonho inútil; a cidade serviu como foco para a vida social ativa, para o conflito e o jogo de interesses, para a experiência das possibilidades humanas, durante a maior parte da história do homem civilizado. Mas hoje em dia essa possibilidade civilizada está adormecida (SENNETT, 2018a, p. 487).
\end{abstract}

A vida moderna, com uma maior necessidade de deslocamentos, a instabilidade das relações sociais, o fortalecimento do individualismo e as pressões por consumo, fez com que a busca por segurança se tornasse um objetivo do indivíduo. Nesse sentido, surgem empreendimentos para condomínios fechados, fortalece-se a rejeição a imigrantes e minorias, e criam-se grupos coesos de apoio mútuo, como associações religiosas e movimentos étnicos. 
A construção de uma comunidade torna-se uma barreira contra as ameaças do mundo, uma maneira de suportar os desafios que a modernidade impõe. “'Cultura” vira sinônimo de fortaleza sitiada, e numa fortaleza sitiada os habitantes têm que manifestar diariamente sua lealdade inquebrantável e abster-se de quaisquer relações cordiais com estranhos" (BAUMAN, 2003, p. 127).

Ao se fechar em comunidades, os indivíduos não se beneficiam do espaço público, que permite o diálogo e convívio entre diferentes em prol de soluções e acordos comuns. A segurança que seria garantida com esses agrupamentos, no entanto, nunca é conquistada plenamente, porque a busca por coesão e a edificação de barreiras entre os de dentro e os de fora, os iguais e os diferentes, criam tensões e pressões contínuas, exigindo um comprometimento cada vez maior dos envolvidos e a rejeição de tudo que possa parecer como um risco à estabilidade.

Nem sempre a formação de uma comunidade é uma ação deliberada dos seus integrantes, mas resultado de exclusões que as antecedem. Por exemplo, Bauman (2003, p. 126127) aponta que quanto mais os imigrantes se sentem acolhidos e respeitados em seu novo país mais eles se mostram abertos à cultura local e menos predispostos a considerar seus valores e crenças como inquestionáveis.

Bauman (2003) reconhece que a segurança é necessária para que se estabeleça um vínculo entre pessoas de comunidades diferentes. Contudo, ela se torna um problema quando a comunidade passa ser vista como um refúgio contra todos os problemas do mundo moderno. Enfraquecer o espaço público não resulta em maior segurança, mas, em longo prazo, apenas intensifica o conflito entre "nós" e "eles" e o sentimento de desconexão com a sociedade.

A pluralidade cultural contribui para o desenvolvimento humano quando há trocas e compartilhamentos entre as comunidades. O reconhecimento da alteridade ${ }^{3}$ é condição para que o debate público possa considerar os mais diversos posicionamentos e desejos. Dessa maneira, a vontade de obter segurança e conseguir lidar com a instabilidade e fluidez da modernidade não deve ser maior do que a percepção que os seres humanos são interdependentes e que o seu futuro se beneficia de políticas e ações coordenadas, em pequenas e grandes escalas.

\footnotetext{
${ }^{3}$ Identificamos a alteridade a partir da relação do sujeito, membro de uma comunidade, com o outro, percebido como diferente por possuir outros valores e referências sociais. A própria delimitação do eu individual e do grupo ao qual ele faz parte é fruto da existência da alteridade, pois se constitui a partir do contraste com o que é externo e estranho. Admitir que o diálogo social requer o contato com o desconhecido é essencial para que ele não seja baseado no medo.
}

InCID: R. Ci. Inf. e Doc., Ribeirão Preto, v. 11, n. 1, p. 191-212, mar./ago. 2020. 
As novas relações de tempo e espaço, possíveis pelo avanço tecnológico que ofereceu meios de transporte e de comunicação de alta velocidade e de alcance global, permitiram o surgimento e disseminação de espaços que Augé (2012) denominou de não lugares. Para ele,

Os não lugares são tanto as instalações necessárias à circulação acelerada de pessoas e bens (vias expressas, trevos rodoviários, aeroportos) quanto os próprios meios de transporte ou os grandes centros comerciais, ou ainda os campos de trânsito prolongado onde são alojados os refugiados do planeta (AUGÉ, 2012, p. 36).

Assim, quando as pessoas não estão fechadas em suas comunidades em busca de proteção, elas atravessam espaços que não estimulam o estabelecimento de contato com desconhecidos. As multidões não são um símbolo de multiculturalismo e de convívio social enquanto cada indivíduo representa apenas um obstáculo físico ou uma ameaça potencial. A facilidade de estar em diversos lugares e encontrar diferentes pessoas, seja por meio de deslocamentos ou do uso de novas tecnologias de comunicação e informação, não resultou em uma maior sociabilidade, já que as condições atuais não se apresentam propícias para a criação de laços sociais e afetivos.

Portanto, ao invés de encontrar um espaço público onde argumentos e sentimentos podem se confrontar e coexistir, seja por negociação ou fusão, o homem moderno se depara com a solidão. A cidade se adapta a exigências de velocidade e eficiência, permitindo que um indivíduo possa trabalhar a quilômetros de distância de sua casa e conversar com membros de sua equipe profissional pela tela de um computador. Por outro lado, ele não se depara com a mesma facilidade para desenvolver relações sociais estáveis no espaço urbano, garantindo momentos de reflexão, de experiências com pessoas de outras culturas, de aprendizado e de questionamento da ordem social.

Sennett (2018b) propõe pensar a cidade a partir das maneiras pelas quais a população se apropria e dá sentido aos espaços ao invés de focar em projetos arquitetônicos para, supostamente, embelezá-la. Desse modo, critica o projeto modernista, presente na Carta de Atenas, que desejava refundar as cidades sem considerar as diversas formas do habitar. Os princípios de Le Corbusier, ao ver a vida social como um elemento de desordem e instabilidade, contribuíram para que o século XX fosse o século da cidade uniforme, funcional e adequada para a circulação de veículos, mas, cada vez mais, ausente de dinamismo e identidade.

Ele propõe um modelo de cidade que é fruto do habitar, que responde às necessidades dos habitantes ao invés de tentar controlá-los. Ele indica o projeto de construção de bibliotecas na periferia de Medellín, Colômbia, como um caminho, pois ofereceu condições para que a 
população se apropriasse do espaço, podendo utilizá-lo para encontros, estudos, reuniões, cursos, entre outras ações adaptadas às suas aspirações (SENNETT, 2018b).

Sennett (2018b) se opõe à rigidez de um caminho exclusivo de deslocamento, a um padrão uniforme de construção, a substituição do caminhar pelo veículo, enfim, a uma cisão entre o construir e o viver, o projeto do arquiteto e os modos de habitar da população. A cidade moderna estaria perdendo a sua capacidade de fomentar a sociabilidade, de oferecer uma experiência compartilhada. Em sua concepção, sociabilidade pode ser compreendida como "o sentimento de uma espécie de fraternidade limitada em relação aos outros, com base na partilha de uma tarefa impessoal. Essa fraternidade limitada se manifesta quando se faz alguma coisa juntos, em vez de estar juntos" (SENETT, 2018b, p. 292-293). Assim sendo, a defesa da esfera pública é primordial para a existência de uma vida em comum, mas, para tanto, a cidade precisa estar aberta ao imprevisto, à ressignificação, a usos não determinados pelos planejadores urbanos.

Ao discutir as possibilidades que a cidade oferece para a sociabilidade, Oldenburg (1989) enaltece o que ele chama de terceiros lugares. Para o autor, o primeiro lugar é a casa; o segundo é o local de trabalho; já o terceiro é onde as pessoas se encontram para vivenciar momentos de lazer baseados na interação e conversa. Esses encontros não possuem um objetivo específico, mas se justificam pelo prazer de passar horas junto de outras pessoas, conversando sobre qualquer tema que possa interessar aos presentes, sem preocupação com o tempo. Esses lugares seriam, na perspectiva do autor, a condição para a vida pública informal.

Oldenburg (1989) ressalta a importância de esses lugares serem abertos ao público, pois eles permitiriam que as pessoas expandissem o seu círculo social e tivessem a oportunidade de conviver com indivíduos de diferentes origens, crenças e valores. Mesmo entre pessoas já conhecidas, esses lugares seriam uma ocasião para conhecê-las melhor, pois elas não estariam presas a papéis exigidos no espaço formal nem a uma hierarquia de funções como no ambiente de trabalho.

Por estimularem a conversação, as pessoas tenderiam a ficar mais próximas, sentadas em uma mesma mesa ou agrupadas em um círculo. Ao poderem falar sobre qualquer assunto, haveria uma grande circulação de informações, o que facilitaria a descoberta de interesses em comum. Para Oldenburg (1989), os terceiros lugares permitem que as pessoas descubram que elas participam de uma comunidade, que existem indivíduos com gostos similares aos delas ao mesmo tempo em que também podem conviver e se divertir com aqueles que possuem uma 
visão de mundo oposta. Nessa perspectiva, eles colaborariam para o bem-estar social, a saúde mental e ações em conjunto.

Oldenburg (1989) apresenta cafeterias, bares e outros lugares de consumo de bebidas e comidas como típicos terceiros lugares. Para ele, esses lugares são de baixo custo de construção e manutenção, podendo surgir até em um pequeno local abandonado. Logo, eles existiriam em quase toda região e seriam acessíveis a uma ampla clientela. Em sua argumentação, esses lugares não seriam apenas espaços de consumo, pois, se assim fossem, seriam não lugares, mas possibilitariam a apropriação pelos seus frequentadores, que os transformariam em um local de encontro e convívio social.

Como os demais autores citados, Oldenburg (1989) aponta que as mudanças tecnológicas do século XX transformaram os terceiros lugares. A televisão preencheu parte do tempo destinado ao convívio com os amigos. Já o carro permitiu que compras fossem feitas de maneira mais rápida e em locais distantes. A gentrificação substituiu pequenos negócios familiares por grandes conglomerados internacionais e a migração de parte da população para os subúrbios a afastou dos seus antigos locais de encontro. Se atualizarmos suas reflexões para o século XXI, podemos lembrar que várias ações, como compras, cursos e atendimentos, podem ser realizadas pela internet, sem sair de casa e estabelecer um diálogo.

Oldenburg (1989) valoriza mais os cafés e bares do que as bibliotecas porque os primeiros exigem menos equipamentos, profissionais, ocupam espaços menores e, por conseguinte, seriam mais fáceis de ser construídos, mantidos e encontrados em vários lugares da cidade. No entanto, Elmborg (2011) lembra que, embora Oldenburg (1989) não foque em seu aspecto comercial e sublinhe que vários são de baixo custo, esses terceiros lugares continuam sendo lugares de consumo e, portanto, não acessíveis a todos. Ainda que o consumo não seja obrigatório, uma pessoa pode se sentir constrangida ao não ter condições financeiras de beber e comer com os seus colegas. O fato de apresentar essa característica faz com que bares, cafés e restaurantes possam ser vistos como não receptivos a alguns perfis de pessoas, desestimulando-os a frequentá-los.

Para Elmborg (2011), há diferenças significativas entre espaços comerciais e públicos e que transformar a biblioteca em um local de consumo e os usuários em consumidores não seria o melhor caminho para confirmá-la como um espaço de convívio social onde pessoas de diferentes origens e classes discutem e se engajam para melhorar a vida em comum. Desse modo, ao invés de tentar adequar a biblioteca ao modelo de terceiro lugar de Oldenburg (1989), 
ele prefere defender a noção de terceiro espaço proposta por Bhabha (1998). Assim, a relevância de um lugar não se constituiria a partir de suas ofertas de atrações e opções de consumo, mas na intersecção entre a estrutura do espaço e as representações atribuídas pelas pessoas a partir de seus usos e apropriações. Espaços públicos, como bibliotecas, seriam propícios para se estabelecerem como terceiros espaços por oferecerem maior liberdade de ressignificação por aqueles que os frequentam e facilitarem a convivência entre pessoas de diferentes culturas. A visão de Bhabha converge com a defesa de Sennett (2018b) por uma cidade aberta, que se transforma continuadamente para se adequar aos anseios e demandas de sua população, muitas vezes em contraposição ao projeto de seus planejadores e arquitetos.

Não há uma solução definitiva para o declínio do espaço público na modernidade, pois, como sublinhamos, ele é resultado de estruturas econômicas, políticas e sociais hegemônicas. Por outro lado, o oferecimento de condições para que as pessoas se reúnam, encontrem com estranhos, estabeleçam laços, troquem experiências e acessem informações podem criar oportunidades locais de engajamento e participação na esfera pública. Algumas instituições, como as bibliotecas, se destacam por dispor de características que preenchem esses requisitos. Sozinhas, elas não resolvem os conflitos do homem moderno, e nem seria esse a sua função, mas podem apresentar caminhos para um novo modelo de sociedade, não alicerçada no consumo e no medo do outro, mas nos ganhos que a colaboração e o compartilhamento de conhecimentos podem trazer para a sociabilidade no espaço público.

Nesse sentido, propomos refletir sobre o papel da biblioteca pública na contemporaneidade e como ela tem se inserido em uma concepção de cidade aberta, onde as suas construções e instituições são receptivas às necessidades dos seus habitantes, sejam elas informacionais ou sociais. 


\section{Bibliotecas e democracia}

Na literatura em Ciência da Informação, as bibliotecas são apresentadas como locais de acesso à informação, contribuindo, portanto, para a democracia. Ao analisar discursos e textos estadunidenses a partir do século XVIII, Buschman (2007) identificou que desde aquele período já existia o argumento de que somente uma população bem informada seria capaz de fiscalizar e cobrar os seus governantes. Porém, a autora aponta uma lacuna entre a retórica sobre o acesso à informação e as ações das bibliotecas no debate público, que pouco se posicionariam para mudanças políticas que fortalecem a participação social.

Conclusão similar chegou Mueller (1984) ao revisar textos redigidos entre 1880 e 1975 , em especial por autores ingleses e norte-americanos, sobre a função da biblioteca. Ainda no século XIX, esses autores enfatizavam o papel educativo da biblioteca e a oportunidade de disponibilizar obras literárias e informações úteis para a população. Contudo, ao contrário de vislumbrar mobilização e mudança social, a biblioteca era vista como um instrumento para manter a ordem pública, uma garantia de filtro para o que os seus usuários iriam ler e a possibilidade de melhor preparar a população para as exigências do mercado de trabalho. Portanto, em muitos textos do século XIX e primeira metade do XX sobre a contribuição da biblioteca para a democracia, vemos uma visão utilitarista e conservadora, de instituição que auxilia na formação educacional, seja afastando a população de leituras inadequadas como ajudando na qualificação profissional.

Segundo Mueller (1984), somente a partir da década de 1960 que ocorreu um maior questionamento sobre a capacidade de a biblioteca atender as necessidades dos grupos mais vulneráveis, de se configurar em um espaço de lazer e de se afirmar como uma instituição cultural em sentido amplo. No entanto, a principal resposta foi ampliar e aperfeiçoar os serviços de acesso à informação, não se aprofundando nas discussões que propomos sobre a biblioteca como um espaço público propício para o engajamento e a transformação social a partir do protagonismo dos cidadãos que a frequentam. A importância dos debates das décadas de 19601970 foi apontar para uma ideia de "bem social" através das opções de acesso e uso da informação. Nessa concepção, a biblioteca difundiria conhecimentos com potencial de melhorar a educação, a cultura e o lazer.

Nos últimos anos, entretanto, têm ganhado fôlego propostas que defendem um maior ativismo das bibliotecas na promoção da democracia, não apenas disponibilizando informações, 
mas criando condições efetivas para a sua circulação, apropriação e uso no espaço público. Assim sendo, novos edifícios incluem amplas salas de convívio e estudo em grupo, setores para a produção de conteúdos pelos próprios usuários, auditórios, áreas de lazer etc. Uma limitação dessa perspectiva é que a falta de recursos financeiros faz com que muitas instituições precisem do apoio do setor privado para atender as mais diversas necessidades informacionais dos seus usuários, o que pode minar a ideia de uma instituição aberta para todos e voltada para a inclusão social.

Willingham (2008) acredita que as bibliotecas públicas continuarão relevantes enquanto existir pessoas sem acesso a computadores e à internet, que não sabem ler, que não podem adquirir todos os livros que desejam e que precisam de um espaço de estudo e de reunião. Todavia, elas podem ser ainda mais importantes se contribuírem para solucionar problemas e propor ações para mudanças na sociedade.

Um novo modelo de biblioteca requer investimentos e profissionais atualizados com as exigências do século XXI, o que também pode gerar pressões para a adequação da instituição. Em alguns países, como na Dinamarca, metade dos usuários das bibliotecas já não as frequentam para emprestar livros, mas como um lugar de encontro, trabalho e estudo. A maioria dos dinamarqueses possui acesso à internet e seis em cada 10 a utilizam para entrar em contato com autoridades públicas. Contudo, as bibliotecas não se tornaram antiquadas, mas passaram a oferecer cursos que aperfeiçoam essa comunicação, tanto a partir de treinamentos para o uso de equipamentos eletrônicos como na navegação de sites governamentais (NIEGAARD, 2011).

\footnotetext{
O que é preciso para produzir um design que forneça o conceito da "nova biblioteca"? São necessários um amplo espaço para os usuários e suas atividades na biblioteca; um layout mais reduzido para a coleção e a alocação de prateleiras; espaço para instalações confortáveis e vastas para descanso; um café; áreas de aprendizagem; áreas de exposição; salas de reuniões; e espaço para concentração individual e acesso a livros e outras formas de mídia. Deve haver abundantes instalações para a pesquisa e internet para os usuários que não trazem seus próprios laptops, além de acesso sem fio à internet para aqueles que os trazem e espaço para instrução on-line (NIEGAARD, 2011, p. 186, tradução nossa).
}

$\mathrm{Na}$ atualidade, as pessoas têm acesso a milhares de informações por diferentes meios de comunicação. É cada vez menos comum uma pessoa sentir necessidade de se deslocar a uma biblioteca para ser informar sobre algo. Porém, essa abundância ou mesmo excesso de informações não têm garantido o seu uso eficaz para melhorar a vida em sociedade. Populações de diversos países vivem em um constante estado de insatisfação com os seus governantes, mesmo com eleições periódicas, pois sentem que não são ouvidas. Ainda que conectadas por 
redes de comunicação, a percepção de abandono e isolamento é comum na contemporaneidade (BAUMAN, 2003). Logo, as bibliotecas despontam, na visão de autores como Willingham (2008), como uma oportunidade para fortalecer o espaço público.

Se, ao longo do século XX, a relação entre democracia e bibliotecas ainda se constituía no acesso à informação, Willingham (2008) acredita que a ênfase atual recai sobre a possibilidade de se constituir e organizar comunidades plurais. Nesse modelo, a biblioteca é um local onde pessoas com diferentes perfis se reúnem para conversar, debater, conhecer umas às outras, ouvir especialistas, aprender e fazer cursos, permitindo que, a partir do diálogo e do compartilhamento de um mesmo espaço, elas tenham condições de encontrar pontos de consenso para a ação coletiva.

Desde o último terço do século passado, autores como Putman (2001) têm observado um declínio da participação dos estadunidenses no espaço público. A popularização dos meios de informação e comunicação (televisão, aparelho de DVD, computador etc.), as constantes migrações em busca de trabalho e a pouca disponibilidade de espaços não comerciais onde cidadãos possam se reunir fizeram com que as pessoas passassem a maior parte do seu tempo em espaços privados, sem se organizar e pressionar por mudanças estruturais no âmbito político e social. O resultado foi um enfraquecimento da democracia, pois elas têm menos oportunidades de conhecer e questionar posicionamentos divergentes, além de resolver problemas de maneira coletiva.

Kranich (2013) lembra que a democracia não se limita ao direito ao voto, mas na capacidade de a população se engajar e ser ouvida pelos seus governantes. Nesse contexto, a biblioteca pode contribuir ao disponibilizar informações, desenvolver serviços e projetos para a sua circulação, além de se estabelecer como local de reunião para que as pessoas possam discutir e se organizar para agir. Apesar de mais meios de comunicação, Kranich (2013) entende que as pessoas não estão mais bem informadas, pois elas perderam a ligação com a sua comunidade. Pequenos jornais locais desapareceram ou foram integrados a empresas globais, a vizinhança tornou-se desconhecida ou estabelece pouco contato e a tecnologia passou a ser uma facilitadora para que as pessoas permaneçam em casa. Assim, elas são informadas de acontecimentos em regiões distantes, mas desconhecem problemas da sua região que afetam as suas vidas diretamente. Quando identificam a origem do problema, se sentem isoladas e incapazes de mudar a realidade. 
Nessa perspectiva, somente preservar e disponibilizar informações não são suficientes para o fortalecimento da democracia, sendo necessário oferecer melhores condições para um maior engajamento da sociedade civil. Desde o final do século XIX, Kranich (2013) identifica discursos e iniciativas que valorizam, ainda que de modo utilitarista, o papel educacional e comunitário da biblioteca, mas até esse reconhecimento teria entrado em declínio a partir da década de 1960, em consonância com as conclusões de Putman (2001). Embora existam bibliotecas ao redor do mundo que promovam iniciativas para o fortalecimento da vida civil, apenas uma participação massiva, crítica e propositiva das bibliotecas no dia a dia das comunidades nas quais elas atuam seria capaz de aumentar a valorização dessa instituição como essencial para uma democracia consolidada. Desse modo, o foco da biblioteca deixa de ser a formação de uma coleção para privilegiar a criação de um ambiente adequado para o debate público, onde o conhecimento é compartilhado, produzido e questionado a partir de uma multiplicidade de pontos de vista. Por meio do diálogo, a biblioteca também se estabelece como um lugar de deliberação, permitindo que a comunidade defina as suas prioridades e as formas de engajamento.

Kranich (2017) defende que as bibliotecas passem de uma posição de informar para envolver. Um cidadão envolvido com as questões de sua comunidade estará mais apto a contribuir para o processo democrático do que aquele que está apenas informado. Ao se tornar um fórum onde os cidadãos podem falar, ouvir e aprender sobre assuntos relacionados aos seus problemas cotidianos, a biblioteca oferece melhores condições para eles agirem.

Nesse contexto, surge a noção de letramento cívico, que pode ser compreendido como o saber encontrar, interpretar e utilizar informações para o bem comum. Ao contribuir para o letramento cívico, a biblioteca exerceria um papel ativo na formação crítica e responsável dos cidadãos (KRANICH, 2017). Esse letramento seria um meio para uma maior competência dos cidadãos em lidar com os desafios e oportunidades do século XXI, como as notícias falsas, os ativismos on-line e as formas de comunicação digital. Algumas bibliotecas se destacam ao realizar parcerias com outras instituições públicas, oferecer acesso gratuito a computadores e à internet e disponibilizar espaços para uso em grupo, mas não basta apenas informar a população, mas engajá-la a partir da constituição de um espaço público.

Essa concepção de biblioteca, no entanto, provoca transformações em serviços tradicionais. Mesmo em bibliotecas cujo foco é o empréstimo de livros, procedimentos de desbaste e descarte são realizados periodicamente para permitir o uso do espaço. Com a 
proposta de oferecer áreas para encontros, reuniões e atividades comunitárias, o lugar destinado aos livros tende a ficar ainda menor. Desse modo, o objetivo de preservar o conhecimento produzido ao longo dos anos é comprometido. Se um dos pilares da democracia é a população ter acesso à informação, reduzir o acervo bibliográfico a apenas aos mais solicitados pelos usuários torna-se uma deficiência, ainda que outras fontes de informação tenham surgido e sejam de fácil acesso.

Ingraham (2015) aponta que, sobretudo nos Estados Unidos e Europa, existe uma pressão para que as bibliotecas se tornem mais atrativas para a população, justificando o investimento público. Nesse sentido, elas buscam atender as necessidades dos usuários em uma perspectiva mais comercial. Ao invés de investirem na promoção da leitura de livros, considerando que parte da população não desenvolveu esse hábito e a leitura ser uma habilidade necessária para a formação crítica dos cidadãos, algumas bibliotecas buscam mapear os desejos mais imediatos dos seus usuários, o que eles consideram atraente e divertido, para oferecê-los como um serviço institucional.

Elmborg (2006) vê a biblioteca como uma zona de contato onde pessoas de diferentes culturas e valores podem se encontrar e interagir. Sua atenção recai sobre a possibilidade de criar um espaço educacional para estudantes aprenderem na biblioteca, mas o conceito de zona de contato pode ser adotado em um sentido mais amplo. Em uma democracia, pessoas com diferentes perfis, condições econômicas e formações educacionais precisam negociar posições e vontades para obter ganhos políticos que beneficiam o maior número de pessoas. A dificuldade para alcançar tal objetivo é não conseguir controlar os conflitos, que podem se tornar destrutivos.

Essa negociação exige concessões, adiamentos e reformulações que geram descontentamentos e desconforto entre grupos. A representação política é uma maneira de possibilitar acordos com um menor desgaste, mas não exclui a importância da participação ativa do cidadão comum na vida pública. Dessa maneira, a biblioteca pode ser um espaço para a formação profissional, o acolhimento de imigrantes e refugiados, o encontro entre amigos, o lazer de idosos, entre outros grupos que raramente frequentam e ocupam o mesmo lugar. Ao não cobrar pelo seu acesso e serviços nem limitar suas ações a um gênero, raça ou idade, ela tem condições de formar um público heterogêneo, um microcosmo das diferenças sociais.

Uma biblioteca ideal, segundo Jochumsen, Rasmussen e Skot-Hansen (2012), visaria quatro objetivos: experiência, envolvimento, empoderamento e inovação. Para tanto, ela 
precisaria de quatro espaços: 1) um para a inspiração, 2) um para o aprendizado, 3) um para o encontro e a convivência e 4) outro para performances. Os autores sublinham que não se referem a espaços físicos delimitados e específicos, mas a usos e funções de espaços que se conciliam e entrecruzam.

1) $\mathrm{O}$ espaço para a inspiração engloba as ações que têm como propósito enriquecer a percepção do mundo e ativar os sentidos. Alguns exemplos são as leituras coletivas, as visitas a lugares a partir da realidade virtual, as visualizações de vídeos etc. 2) O espaço para o aprendizado oferece acesso à informação em diferentes suportes e promove atividades formais e informais para o conhecimento. A aprendizagem ocorre tanto por meio de jogos, atividades artísticas e apresentações como por meio de cursos periódicos produzidos por especialistas. Esse espaço também serve para estudantes estudar ao longo do dia, profissionais liberais redigirem projetos e relatórios e desempregados escreverem os seus currículos. 3) O espaço para encontro e convivência dispõe de sofás, mesas com computadores, jornais e revistas que as pessoas podem consultar de forma compartilhada. Nele, os usuários tomam café com os amigos, marcam um encontro, fazem uma reunião. Embora deva existir um lugar para encontros não programados, os bibliotecários também podem reservar algumas áreas para incentivar a discussão e a busca de soluções para problemas coletivos. Assim, as pessoas que se encontram na biblioteca são estimuladas a participar de um bate-papo sobre um assunto específico. 4) Por fim, o espaço para performances é um espaço para a produção artística e intelectual. A partir de recursos de texto, som e imagem, os usuários criam objetos, desenvolvem jogos, gravam vídeos, escrevem textos, entre outros. Profissionais, como programadores, designers e escritores, podem oferecer oficinas para que o público aproveite os recursos oferecidos (JOCHUMSEN; RASMUSSEN; SKOT-HANSEN, 2012).

Para John (2016), as bibliotecas estão se transformando em lugares de coleções para conexões. No entanto, adequar as bibliotecas às mudanças tecnológicas e oferecer espaços onde as pessoas possam se encontrar e compartilhar informações exige uma arquitetura adequada. Entre 2015 e 2016, ela visitou 34 bibliotecas de 12 países da América do Norte e da Europa para observar com elas estão lidando com esse novo contexto. Segundo a autora (JOHN, 2016), as três principais razões pelas quais as pessoas frequentam a biblioteca são a leitura, o aprendizado e a reunião. Sendo assim, a sua arquitetura deve dispor de espaços para essas experiências. 
Uma solução encontrada foi a criação de bibliotecas com amplos espaços abertos e móveis modeláveis que podem ser adaptados de acordo com as necessidades. A decoração e o mobiliário podem criar separações entre áreas para crianças e adultos, de leitura e estudo e assim por diante, sem precisar erigir inúmeras paredes. Como as bibliotecas dispõem de diversos serviços e atividades simultâneas, é importante que elas tenham a habilidade de responder às demandas dos seus usuários reformulando a organização do espaço. Espaços abertos e de fácil circulação ainda ajudam encontros casuais e possibilitam a interação (JOHN, 2016).

A localização é outro fator que afeta a sua visitação, pois bibliotecas em áreas centrais e próximas de outros serviços públicos tendem a possuir mais usuários. John (2016) lembra que shopping-centers e hospitais sempre analisam os serviços oferecidos nas redondezas no momento de escolher o local para a sua construção e que o mesmo deve ser feito com as bibliotecas. Se pensarmos em uma biblioteca a partir de sua contribuição para o espaço público, devemos considerar a sua relação com as instituições do entorno e como o seu prédio se integra à paisagem urbana. Se as pessoas frequentam a biblioteca como um terceiro espaço e não apenas para retirar um livro ou perguntar uma informação, elas irão precisar de um local para se alimentar, meios de transporte para se locomover e de segurança para levar computadores pessoais e outros equipamentos. Logo, se a biblioteca não oferece apenas um serviço rápido, mas se constitui em um lugar onde as pessoas podem passar a maior parte do seu dia, podendo viver momentos de lazer, trabalho e estudo dentro dela, as condições de alimentação, segurança e mobilidade no seu entorno também devem ser avaliadas.

Defender a biblioteca pública como uma oportunidade para facilitar e fortalecer a vida social requer reconhecer os desafios de adotar tal perspectiva. Se ainda são necessárias, especialmente na bibliografia nacional, discussões teóricas sobre a formação de um domínio público nessa instituição, a execução dessa visão em suas práticas cotidianas soa ainda mais complexa. Entretanto, em um período de incertezas e crise na representação política, repensar a biblioteca pública também é uma ocasião para refletir sobre o futuro da democracia. 


\section{Considerações finais}

Ao longo do século XX, autores como Habermas (2014), Sennett (2018a; 2018b) e Arendt (2019) apontaram o declínio do espaço público. Em perspectivas que se complementam, eles discutiram como a modernidade permitiu o surgimento de concepções de trabalho, tempo e espaço que modificaram ou até mesmo impossibilitaram o debate político. O capitalismo favoreceu o domínio do espaço privado sobre o público enquanto os Estados nacionais, ao adotarem os seus princípios, priorizaram ações que visavam o enriquecimento financeiro em detrimento do investimento em instituições que potencializam a vida e a organização social.

Em busca de segurança e pertencimento, o homem moderno se fechou em comunidades, dificultando o encontro e o convívio público. Os espaços externos passaram a se restringir a lugares (ou não lugares) de circulação, consumo e trabalho. Os terceiros lugares apresentados por Oldenburg (1989), por exemplo, possuem características que podem diferenciar os seus frequentadores pela sua capacidade de consumo, transformando o público em clientela. A concentração de renda e o modelo arquitetônico que prevaleceu no século XX, tendo o arranhacéu como um dos seus símbolos, também não estimularam uma ideia de cidade aberta, onde o diálogo surge do acaso, o imigrante é bem-vindo e o desconhecido é convidado a participar do debate. Recorrendo à Arendt (2019), concordamos que o enfraquecimento do domínio público é um impulso para o totalitarismo.

Diante desse quadro, buscamos pensar em formas de resistência ou reinvenção dos espaços públicos, especialmente por meio de instituições. Para tanto, focamos em uma instituição frequentemente desprezada pelo poder instituído, carente de recursos e muitas vezes vista como obsoleta: a biblioteca pública. Sem negar os seus problemas, abordamos como ela se insere e contribui para a manutenção do espaço público ao se estabelecer como uma instituição de convívio, debate, aprendizado e trocas de experiências a partir da oferta de serviços, lugares e recursos informacionais. Por conseguinte, contribuímos para as reflexões sobre a sua missão.

Entendemos que essa discussão é ainda mais relevante para o contexto brasileiro considerando um conjunto de fatores: baixo investimento em bibliotecas públicas, expressiva desigualdade social, dificuldade de locomoção nos grandes centros, sobretudo nas suas periferias, violência urbana que fomenta pedidos por segurança e proteção e restrições de acesso a um sistema de ensino de qualidade pelas classes sociais mais baixas. 
Pensar a biblioteca pública no Brasil exige ponderar essas características que, em curto prazo, tornam a sua constituição em um espaço público efetivamente democrático e inclusivo ainda mais difícil. Por outro lado, o reconhecimento desses problemas colabora para evidenciar os diversos benefícios que o país obteria se investisse nessa instituição, atenuando conflitos sociais que impedem uma maior participação social na vida pública.

O espaço público depende de estruturas sociais e políticas que extrapolam o funcionamento de uma biblioteca, mas desejamos mostrar que a sua relevância aumenta ao admitirmos a crise de representatividade política e de debate público, o que tem se acentuado nas primeiras décadas do século XXI. Portanto, defender um mundo com maior diversidade, circulação do conhecimento e abertura para o outro inclui reconhecer o papel da biblioteca pública enquanto uma das instituições que sustentam a democracia.

\section{Referências}

ARENDT, Hannah. A condição humana. 13. ed. Rio de Janeiro: Forense Universitária, 2019.

AUGÉ, Marc. Não lugares: introdução a uma antropologia da supermodernidade. 9. ed. Campinas: Papirus, 2012.

BAUMAN, Zygmund. Comunidade: a busca por segurança no mundo atual. Rio de Janeiro: Zahar, 2003.

BERMAN, Marshall. Tudo o que é sólido desmancha no ar. São Paulo: Companhia das Letras, 2007.

BHABHA, Homi K. O local da cultura. Belo Horizonte: Editora UFMG, 1998.

BUSCHMAN, John. Democratic theory in library information science: toward an emendation. Journal of the American Society for Information Science and Technology, [s. l.], v. 58, n. 10, p. 1483-1496, 2007. DOI: https://doi.org/10.1002/asi.20634. Disponível em: https://onlinelibrary.wiley.com/doi/abs/10.1002/asi.20634. Acesso em: 31 ago. 2019.

ELMBORG, James K. Libraries as the spaces between us: recognizing and valuing the third space. Reference \& User Services Quarterly, [s. l.], v. 50, n. 4, p. 338-350, 2011. DOI: https://doi.org/10.5860/rusq.50n4.338. Disponível em: https://journals.ala.org/index.php/rusq/article/view/3297. Acesso em: 28 jan. 2019.

ELMBORG, James K. Libraries in the contact zone: on the creation of educational space. Reference \& User Services Quarterly, [s. l.], v. 46, n. 1, p. 56-64, 2006. DOI: https://doi.org/10.5860/rusq.46n1.56. Disponível em: https://journals.ala.org/index.php/rusq/article/view/2962. Acesso em: 01 set. 2019. 
HABERMAS, Jürgen. Mudança estrutural da esfera pública: investigações sobre uma categoria da sociedade burguesa. São Paulo: Editora Unesp, 2014.

HALBWACHS, Maurice. A memória coletiva. São Paulo: Centauro, 2004.

INGRAHAM, Chris. Libraries and their publics: rhetorics of the public library. Rhetoric Review, [s. l.], v. 34, n. 2, p. 147-163, 2015. DOI:

https://doi.org/10.1080/07350198.2015.1008915. Disponível em:

https://www.tandfonline.com/doi/abs/10.1080/07350198.2015.1008915. Acesso em: 23 ago. 2019.

JOCHUMSEN, Henrik; RASMUSSEN, Casper Hvenegaard; SKOT-HANSEN, Dorte. The four spaces - a new model for the public library. New Library World, [s. l.], v. 113, n. 11/12, p. 586-597, 2012. DOI: https://doi.org/10.1108/03074801211282948. Disponível em: https://www.emerald.com/insight/content/doi/10.1108/03074801211282948/full/html. Acesso em: 27 ago. 2019.

JOHN, Gemma. Designing libraries in 21st century: lessons for the UK. London: Winston Churchill Memorial Trust, 2016. Disponível em:

https://www.wcmt.org.uk/fellows/reports/designing-libraries-21st-century-lessons-uk. Acesso em: 17 jul. 2019.

KRANICH, Nancy. Libraries and strong democracy: moving from and informed to a paticipatory 21 st century citizenry. Indiana Libraries, [s. l.], v. 32, n. 1, p. 13-20, 2013. Disponível em: http://journals.iupui.edu/index.php/IndianaLibraries/article/view/4228. Acesso em: 19 ago. 2019.

KRANICH, Nancy. Libraries: reuniting the Divided States of America. The Library Quarterly, [s. l.], v. 87, n. 4, p. 419-429, 2017. DOI: https://doi.org/10.1086/693495. Disponível em: https://www.journals.uchicago.edu/doi/10.1086/693495. Acesso em: 22 ago. 2019.

MUELLER, Suzana Pinheiro Machado. Bibliotecas e sociedade: evolução da interpretação de função e papéis da biblioteca. Revista da Escola de Biblioteconomia da UFMG, Belo Horizonte, v. 13, n. 1, p. 7-54, 1984. Disponível em:

https://brapci.inf.br/index.php/res/v/74223. Acesso em: 16 jun. 2020.

NIEGAARD, Hellen. Library space and digital challenges. Library Trends, [s. l.], v. 60, n. 1, p. 174-189, 2011. DOI: https://doi.org/10.1353/lib.2011.0028. Disponível em: https://www.ideals.illinois.edu/handle/2142/31867. Acesso em: 30 ago. 2019.

OLDENBURG, Ray. The great good place: cafes, coffee shops, community centers, beauty parlors, general stores, bars, hangouts and how they get you through the day. New York: Paragon House, 1989.

PUTMAN, Robert. Social capital: measurement and consequences. Isuma: Canadian Journal of Policy Research, [s. l.], v. 2, p. 41-51, 2001. Disponível em:

http://smg.media.mit.edu/library/putnam.pdf. Acesso em: 01 out. 2019. 
SENNETT, Richard. Construir e habitar: ética para uma cidade aberta. Rio de Janeiro: Record, 2018a.

SENNETT, Richard. O declínio do homem público: as tiranias da intimidade. 3. ed. Rio de Janeiro: Record, 2018b.

WILLINGHAM, Taylor L. Libraries as civic agents. Public Library Quarterly, [s. l.], v. 27, n. 2, p. 97-110, 2008. DOI: https://doi.org/10.1080/01616840802114820. Disponível em: https://www.tandfonline.com/doi/abs/10.1080/01616840802114820. Acesso em: 30 ago. 2019.

Artigo submetido em: 26 out. 2019

Artigo aceito em: 16 jun. 2020 